\title{
Wind Generation and Power System Interaction Analysis using Probabilistic Techniques
}

\author{
Marco Ortiz ${ }^{1}$, Juan Ríos ${ }^{1}$, Manuel Acosta ${ }^{1}$ \\ ${ }^{1}$ Electrical Systems Planning Division \\ CVG EDELCA \\ Caracas, Venezuela \\ Phone number: +58 212 9502890, e-mail: maortiz@edelca.com.ve, jrios@edelca.com.ve, macosta@edelca.com.ve
}

\begin{abstract}
Energy power from renewable sources, especially wind turbine generators, are being considered as an important generation alternative in the electrical power systems around the world due to their non contaminant nature and low environmental effects. In particular, the power supplied by wind generators is widely random following the random nature of weather conditions; therefore a probabilistic approach during planning seems much more appropriate than the deterministic approach actually used in the electrical utilities. This paper presents a methodology that allows the application of probabilistic analysis, thru the use of programming tools, in the load flow planning studies. The methodology described provides the opportunity to obtain the steady state response in systems where wind power exists using a wind power generation model (WPGM) and an iterative routine to the load flow analysis considering each value of generation of the wind sources.
\end{abstract}

A wind power generation model (WPGM) was developed using a random wind speed generator. The random wind speed generator describes the Weibull distribution of wind measurements, and then using Montecarlo simulation techniques, a program in Visual Basic executes the automatic evaluation of random samples of speed of wind considering the characteristic power curve of a wind turbine, obtaining a widely database of wind generation conditions.

As a result of the investigation, a computational tool was developed in order to use it, in combination with the PSS/E load flow analysis software, for steady state power system analysis. The methodology was used as an assessment tool to identify the effects of wind turbines generation into the substation voltages and power flow profiles in the power network, for a wind farm project intended to be installed in Margarita Island. The analysis aimed to identify the transmission adjustments, reinforcements and expansions needed to guarantee the wind farm project integration successful into the power system.

\section{Keywords}

Wind energy, Weibull distribution, Montecarlo simulation, load flow analysis.

\section{Introduction}

The electrical generation from the wind resource is one of the fastest growing energy sources, and is regarded as an important alternative to traditional power generation sources [1]. The fact that wind power penetration continues to increase has motivated a need to develop more widely applicable methodologies for evaluating the benefits and effects of adding wind turbines to conventional generating system.

World-wide situation referred to high fuel costs, new wind generation technologies availability and gas emissions regulations, cause that the wind generation must be considered as a important alternative in systems with high wind resource potential, as Margarita Island. Wind power implementation in Nueva Esparta state, has been considered in context of other generation alternatives in order to improve the load-generation balance deficit in this important region of Venezuela [2]. Considering the random nature of the wind resource, it is necessary to develop and to evaluate programming tools that allow characterizing electrical response of power systems considered wind power generation.

Many investigations have been carried out in the past regarding the effects of the wind turbines on the steady state operation of the electrical systems. In particular, the power supplied by wind is widely random following the random nature of weather conditions; therefore a probabilistic approach during planning seems much more appropriate [3].

The methodology described in this paper provides the opportunity to estimate the steady state power system behavior containing wind power generation. A wind power turbine generator (WTG) is modeled as a multistate unit represented by a number derated power output states using the wind speed model for the wind farm location and the power curve of the WTG. The model appropriately reflects the fluctuating characteristics of the site specific wind.

A WTG produces no power in the absence of sufficient wind and under these circumstances makes no contribution to the power system [4]. There is a definable probability that there will be insufficient wind at a given site. The probability, however, of there being no wind simultaneously at two widely separated independent wind sites is much less, and locating WTG at independent wind sites should be of considerable benefit in improving the power system performance. 


\section{Wind utilisation as an energy source}

Wind represents an indirect form of the originating energy of the sun and the rotational Earth movement. The not uniform heating of the terrestrial surface, as well as the unequal thermal characteristic of the terrestrial and aquatic masses of the planet altogether with the rotational movement, creates the air movement that we know like wind, which circulate around the terrestrial surface following a global circulation pattern.

For wind power quantification three basic characteristics are needed, these are: wind speed and direction, the topographic characteristics of the study area and the air density [5]. The greater relevance parameter is the wind speed, because wind power is a proportional variable to the cube of wind speed as show in (1).

$$
P=\frac{1}{2} \rho * \mathrm{~A} * V^{3}
$$

Where $\rho$ is the air density $(\mathrm{kg} / \mathrm{m} 3), \mathrm{V}$ is wind speed $(\mathrm{m} / \mathrm{s})$ and $A$ is the rotor area $(\mathrm{m} 2)$.

\section{A. Wind speed statistical model}

The wind speed changes continuously and to obtain estimations in long term statistical methods are used. The Weibull probability density function has been widely used in the field of engineering to describe variations of the wind speed [6]. The Weibull model can be obtained using (2).

$$
f(v)=\frac{\alpha}{\beta}\left[\frac{v}{\beta}\right]^{\alpha-1} * e^{\left(-\left(\frac{v}{\beta}\right)^{\alpha}\right)}
$$

Where " $v$ " represents wind speed, " $\alpha$ " is the shape factor and " $\beta$ " is the scale factor of Weibull probability density function.

\section{B. Weibull parameters estimation}

With the data field of wind speed measurements, it is possible to be obtained the representative parameters of the Weibull probability density function from the wind speed average defined as the average arithmetic of the measurements, described in (3).

$$
\bar{V}=\left(\frac{1}{N} * \sum_{i=1}^{N} v_{i}\right)
$$

Where $\mathrm{N}$ is the total number of wind speed measurements and $\mathrm{Vi}$ the wind speed measurement.

From the speed average data the standard deviation is known, defined as it follows:

$$
\sigma=\frac{1}{N} *\left(\sqrt{\sum_{i=1}^{N}\left(v_{i}-\bar{V}\right)^{2}}\right)
$$

Obtained the wind speed average value and the standard deviation, the following relations are used:

$$
\begin{gathered}
\bar{V}=\int_{0}^{\infty} v f(v) d v=\beta^{*} \Gamma\left(1+\frac{1}{\alpha}\right) \\
\sigma^{2}=\int_{0}^{\infty}(v-\bar{V})^{2} f(v) d v=\beta^{2}\left\{\Gamma\left(1+\frac{2}{\alpha}\right)-\Gamma^{2}\left(1+\frac{1}{\alpha}\right)\right\}
\end{gathered}
$$

Where " $\Gamma$ " is the Gamma function.

Both equations can be solved of simultaneously to obtain the form factor "' and the scale factor "'; but it is a complex process, for that reason to obtain these parameters some authors recommend the Justus approach [7] defined by (7).

$$
\alpha=\left(\frac{\sigma}{\bar{V}}\right)^{-1.086}
$$

From this the scale factor can be obtained using (5).

\section{Wind model random generator}

Obtained the Weibull function parameters, was elaborated a wind speed random generator, using "random" function available in a spreadsheets application like Office Excel, altogether with the statistic theory tool denominated Inverse Transformed method, through which can be generated pseudo-random numbers that follow certain known functions of density [8]. The inverse transformed method consists of:

$$
F(V)=1-e^{\left(-\left(\frac{V}{\beta}\right)^{\alpha}\right)}=R
$$

Where $\mathrm{R}$ is a uniformly distributed number in $[0,1]$ interval.

Solving $F(R)^{-1}$, it is obtained the pseudo-random number generator:

$$
F(R)^{-1}=\beta \times[-\ln (1-R)]^{1 / \alpha}=V
$$

Where " $\alpha$ " is the shape factor and " $\beta$ " is the scale factor of Weibull probability density function and $\mathrm{R}$ is a uniformly distributed number in $[0,1]$ interval.

Since the supply of wind power generators market at world-wide level is extensive, a representative sample of four wind turbines was selected to restrict the reach of the investigation and to grant the future user the versatility to define the capacity of generation turbine. Also, affectation of wind speed values for each machine was modeled using an algorithm that reflects wind dispersion principle of a same wind location. 
Using VBA (Visual Basic for Application) programming language, was created an iterative routine that allow to structure the Montecarlo simulation process, to obtain multiple generation power values in MW by means of evaluation of random wind speeds values in two wind sites with characteristics defined previously by user (machine number, nominal power, hub height of wind turbine, wind incidence).

\section{Iterative load flow}

In order to obtain the electrical system response by multiple wind generation values affectation was developed simulation software of iterative load flow making use of IPLAN (PSS/E programming tool). The program code was developed by subroutines; as general result the program executes the flow chart represented by figure 1.

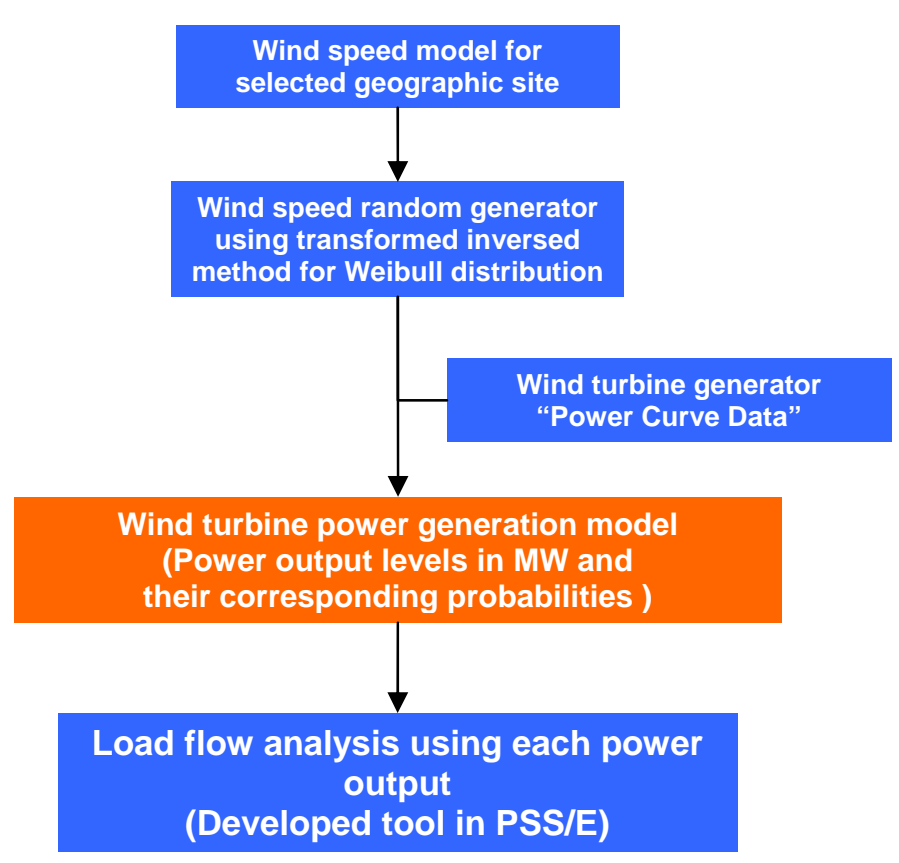

Figure 1. Iterative load flow program.

\section{Performance benefits of independent wind energy sources}

A comparative study was made in order to establish the effect of wind incidence in a same location. The affectation of voltage profile in all system buses was simulated carrying out the analysis of iterative load flow using each power output with variations in the definition of the incident wind number, obtaining as a result that electrical output of wind farm is much more constant when we defined wind speed independence in the affectation of wind site farm, as consequence we obtain a better performance electrical system response. The variability reduction of the wind generation in a wind farm, it must that the wind structure, space and temporary, is less correlated as the distances between turbines become greater.

The voltage profiles in a system bus considering the effect of wind dispersion it is reflected in figures 2 and 3 :

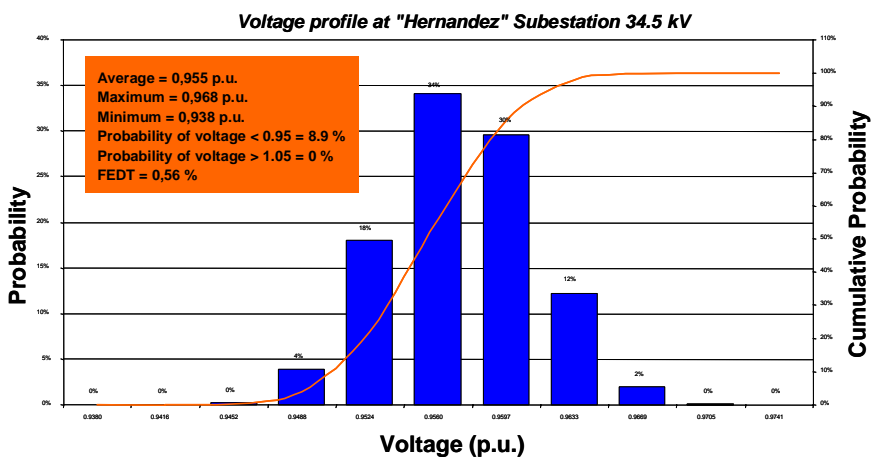

Figure 2. Voltage profile using ten incident wind speed values.

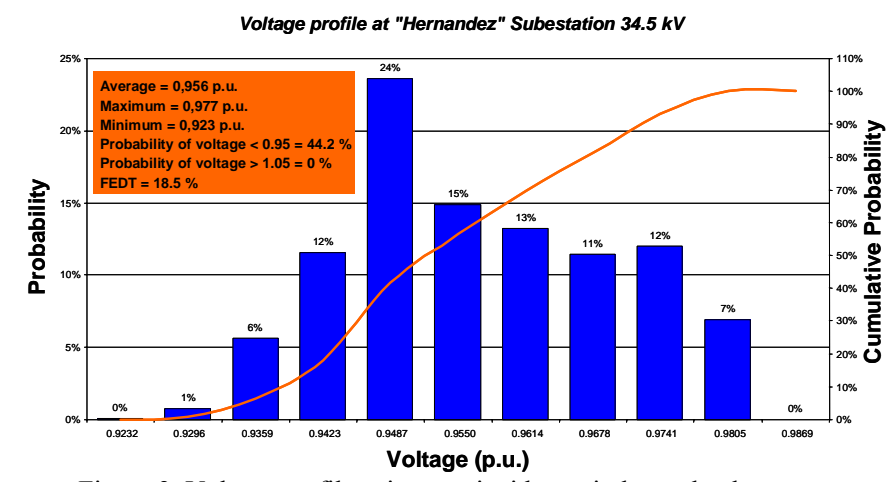

Figure 3. Voltage profile using one incident wind speed value.

Taking into account the shown figures, knowing that the scene of less optimistic simulation is represented by the affectation of a single value of wind speed in a wind farm, it was selected like premise, the analysis of the practical case considering this condition of wind incidence.

\section{System adequacy}

Figure 4 represents the electrical system modeled in the load flow program (PSS/E), including the proposed location for the two wind farm projects.

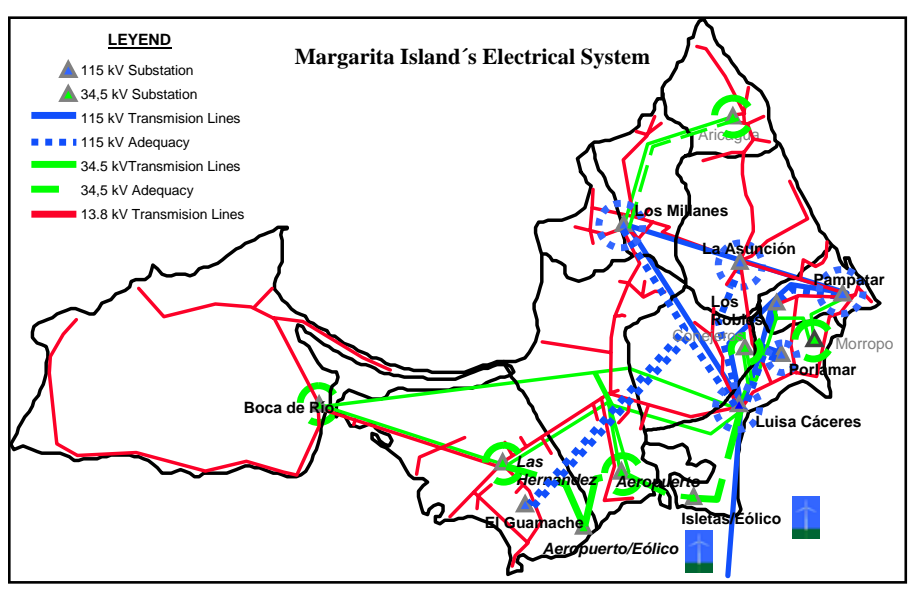

Figure 4. Margarita island's electrical system.

The map reflects the system adjustments due to the inclusion of the two wind farms, considering the following operation criteria in steady state:

1. Maximum variation of $5 \%$ of the nominal voltage is allowed, either in normal condition or $\mathrm{N}-1$ condition. 
2. Overload of any equipment in normal conditions of operation is not allowed.

3. Under simple contingency, a $20 \%$ of overload (of the nominal capacity) are allowed in transformers and lines. Maximum lines load could not exceed the emergency capacity for $100{ }^{\circ} \mathrm{C}$ of loadability. The Equivalent Frequency Voltage Deviation indicator (FEDT in Spanish) established in [9] referred to the number of measurements outside the authorized voltage cannot be greater than $3 \%$.

\section{Conclusions}

The wind power generation model (WPGM), allows to obtain a model of electrical generation for a possible wind site location that it can be applied to different regions, whenever is had reliable data of wind measurements of the selected site. This model allows to simulate the behavior of the wind for the obtaining of multiple values of electrical power through the application of Montecarlo techniques.

It is very important to obtain suitable wind speed simulation models and appropriate techniques to develop power generation model for Wind Turbine Generator in load flow analysis.

The developed tool allows to obtain a probabilistic approach to calculate the voltage, and power flows based not simply on expected average or peak values of power sources and loads, but to obtain the complete spectrum of all probable values together with their respective probabilities.

It is demonstrated by means of use of simulations, that the independence of the wind incidence has a significant positive impact to improve electrical system performance, and therefore, locating the wind farms in multiple sites with low wind correlation the performance of the system can be improved.
It is important to indicate, that the problem of the variability of the wind resource, is not a restriction for electrical power system response analysis before the inclusion of wind farm. Nevertheless, the development of tools is fundamental that allow to represent the intrinsic fluctuations in the generation of electricity from a random resource like the wind.

\section{References}

[1] Karki R., Hu P., Billinton R., "A simplified wind power generation model for reliability evaluation". EN: IEEE Trans. Energy Conversion. - Vol. 21, No2 (2006), p.p 533 - 540.

[2] Acosta M., Ríos J., Álvarez E. “Análisis de prefactibilidad de generación eólica en la Isla de Margarita considerando desplazamiento de inversiones en transmisión, generación y posibles beneficios derivados de los certificados de emisiones". - EN: Revista Especial VI Jornadas Profesionales CVG-EDELCA. Vol. 1, N¹ (2006), p.p $131-135$.

[3] Hatziargyriou N., Karakatsanis T., Papadopoulos M., "Probabilistic load flow in distribution systems containing dispersed wind power generation". - EN: IEEE Trans. Energy Conversion. - Vol. 8, $\mathrm{N}^{\circ} 1$ (1993), p.p $159-165$.

[4] Billinton R., Bai G., Generating capacity adequacy associated with wind energy. - EN: IEEE Trans. Energy Conversion. - Vol. 19, $\mathrm{N}^{\circ} 3$ (2004), p.p 641 646.

[5] Universidad de Zaragoza. "Apuntes Energía Eólica”, - Zaragoza: España, 2005. Capítulo I: p.p 1 - 17.

[6] Ministerio de Recursos Naturales de Canada. $<$ http://www.retscreen.com $>$ [Consulta: 2006]

[7] Justus C., "Wind and system performance".- USA: Philadelphia: Franklin Institute Press., 1978.

[8] Tarifa E., "Teoría de modelos y simulación. Generación de números aleatorios". Argentina: Universidad de Jujuy, 2004.

[9] Ministerio de Energía y Petróleo. "Normas de calidad del servicio de distribución de electricidad". Venezuela (2004). 